\title{
NOTE ON TERMS
}

Throughout this book I discuss questions of racial identity and mental illness. Doing so raises inevitable problems. How to investigate the meaning of terms that we cannot avoid but use ourselves? How can language exist as both the object of analysis and its instrumental terms? How can we avoid imparting unintended meaning? In the chapters that follow I use the term 'European' to describe people who were judged by contemporaries to be European. Likewise, I use the terms 'madness', 'insanity' and 'mental illness' not as precise or scientific designations of my own but as broadly encompassing terms to describe the fact of a person's treatment at a psychiatric institution.

Before this research began, ethics clearance was obtained from the universities of Leeds and Nairobi. A serious concern was to protect the anonymity of psychiatric patients and their families. In what follows, all the names of individuals treated at the Mathari Mental Hospital, as well as their family members, have been changed. In addition, where appropriate, secondary information - relating, for example, to place names, details of an individual's background and employment or the circumstances of their admission - have also been changed. In making these alterations I have endeavoured not to distort the analysis of patient life-histories. Most importantly, I hope that I have written with sympathy and respect towards those whose stories I have told. 